\title{
El juego del calamar: Una perspectiva profesional desde la Orientación
}

\author{
Gabriela Chacón-Fonseca \\ Sistema de Colegios Humanísticos Costarricenses \\ Heredia, Sarapiquí \\ chaconfgabriela@gmail.com \\ (iD) https://orcid.org/0000-0002-1740-8235 \\ German González-Sandoval \\ Universidad Nacional \\ Heredia, Costa Rica \\ german.gonzalez.sandoval@una.ac.cr \\ https://orcid.org/0000-0002-9149-7635
}

RECIBIDO: 23 de octubre de 2021 / ACEPTADO: 27 de octubre de 2021

La obra que se reseña a continuación es la serie producida en Corea del Sur, en género de drama, lanzada en setiembre del 2021, mediante el servicio de streaming Netflix. En español se ha titulado El juego del calamar, en inglés Squid Game, mientras que su título original es Ojingeo Geim.

El director y guionista es Hwang Dong-hyuk, y tiene en el reparto a Lee Jung Jae (Seong GiHun, n.o 456), Park Hae Soo (Cho Sang-Woo, n.․ 218), Heo Sung Tae (Jang Deok-Su, n. 101), Wi Ha Joon (detective Hwang Jun-Ho), Oh Young Soo (Oh Il-Nam, n.o 001), Hoyeon Jung (Kang Sae-Byeok, n.o 067), Kim Joo Ryung (Han Mi-Nyeo, n.o 212), Lee Byung Hun (In-Ho, líder enmascarado), Gong Yoo (reclutador), John D. Michaels (VIP 1), Geoffrey Giuliano (Vip 4) y Daniel C. Kennedy (VIP 2). Su primera temporada se compone de nueve episodios, con una duración aproximada de 60 minutos cada uno.

El juego del calamar trata sobre una selección de personas que, por motivos diversos, se encuentran en una situación económica agobiante, los cuales son seleccionados por un reclutador, quien les ofrece la posibilidad inmediata de ganar dinero mediante un "inocente" juego, llamado Ddakji; sin embargo, al perder y no tener dinero, pagarán con una fuerte cachetada. Esto se convierte en el enganche para la vinculación a un juego mayor, en el que se ofrece un premio millonario y del cual no se conocen más condiciones o reglas, excepto que serán recogidos en el lugar que se indique.

La trama de la serie se desarrolla con la llegada de un total de 456 personas jugadoras a un lugar cuya ubicación geográfica y tiempo de permanencia se desconocen, son recibidas por un grupo de enmascarados que se encargan de la logística de los juegos, los cuales son promovidos por y para unos personajes llamados VIP, quienes representan el poder económico. En cada episodio de la serie se plantea un juego infantil individual o grupal, de competencia y destreza, propios del contexto surcoreano; sin embargo, algunos tienen similitudes con juegos occidentales, por ejemplo, luz verde-luz roja es semejante a 1, 2, 3 quesito stop, el panal, la cuerda, las canicas, el puente de cristal simulando rayuela y el juego del calamar. Los juegos son reconceptualizados, debido a que tienen la intención de ir eliminando diversa cantidad de jugadores con la pérdida de sus vidas; no obstante, se generan alianzas impulsadas por la avaricia, pues fuera de los juegos planteados por el líder, buscan eliminar a otros, siendo que, al finalizar, el jugador 456 es el único ganador. 
De los aspectos por analizar en cada episodio de esta serie, resalta cómo el sistema capitalista moderno ha marcado en la sociedad un deseo irracional por vivir con las mejores y más lujosas casas, autos y vacaciones, a pesar de que la persona no cuente con recursos económicos suficientes que permitan adquirir esos bienes. Entonces, esto lleva a que las personas accedan a grandes endeudamientos con el único propósito de satisfacer la necesidad consumista, para alcanzar esa vida idealizada.

Esta perspectiva errante requiere trasladarse hacia lo fundamentado por Valdés (2014), a través de la conceptualización del sentido de la vida propuesto por Frankl, pues la persona requiere resignificarse y resignificar su propósito, con la intención de buscar su bienestar integral y felicidad, dados por lo que posee y la manera en que lo ha alcanzado, dejando de lado la frustración por lo que no tiene o desea obtener.

Otro elemento que se evidencia es el planteamiento, ilegal, de la renuncia a los derechos humanos (universales, esenciales e imprescriptibles), a través de la firma de un contrato, dejando a merced de la organización el poder de decisión sobre la persona. De esta manera, la deshumanización se representa en diversos momentos, por ejemplo, en la agresión hacia la integridad de la persona cuando debe permitir que se le golpee la cara como medio de castigo por la pérdida de un juego, además de la desvalorización de la vida, pues las personas son incitadas y están dispuestas a poner en riesgo su vida con el objetivo de ganar el premio y, de esta manera, resolver las dificultades que le preocupan.

A través de lo comentado, se debe señalar que resulta preocupante el modo en que esta serie permea, de manera influyente, en la sociedad costarricense. En el contexto cotidiano, se escucha fácilmente la manera en que personas de diversas edades, grupos de trabajo, familias y otros, ponen en práctica los juegos mencionados, utilizan imágenes referentes a la serie en redes sociales y sus contextos inmediatos e, incluso, celebran fiestas infantiles con su temática. Por todo eso, preocupa que se dé una normalización de la violencia, una transformación de la realidad y no se desarrolle el pensamiento crítico alrededor de la información transmitida en los diferentes canales de comunicación.

Aunado a lo anterior, preocupa la forma en que se deja de lado la práctica de juegos tradicionales costarricenses y, en su lugar, se asumen patrones ajenos, lo que genera pérdida y transformación de valores auténticos y congruentes con la idiosincrasia costarricense, en detrimento de la identidad colectiva e individual.

La puesta en ejecución de estas actitudes conlleva una fuerte influencia en el inconsciente colectivo, pues de manera solapada e imperceptible, pero generalizada, se asume naturalmente pensamientos y conductas violentas, discriminantes y de poca identidad personal auténtica, pues, como lo indican Chernicoff y Rodríguez (2018):

Autoconocerse implica desarrollar la habilidad de dirigir la atención hacia el propio mundo interno y tomar conciencia de sí mismo, entender las emociones, su influencia en la experiencia y la conducta; y expresarlas de forma adecuada al contexto. Se relaciona con las actitudes y creencias del individuo sobre sí mismo, el aprecio por sí mismo y la confianza en su capacidad para lograr metas. (p. 31)

De esta manera, se plantea un desafío para la persona profesional de la Orientación en el afrontamiento de los efectos sociales e individuales que genera la serie reseñada, pues no es posible asumir una posición pasiva y desinteresada, debido a que la responsabilidad depositada en el quehacer orientador, desde la función ética, implica el desarrollo de acciones para fortalecer a la persona desde su propia identidad, del contexto inmediato y emergente. 
Así mismo, es necesario que desde la disciplina se promuevan espacios de sensibilización, análisis y reflexión desde el pensamiento crítico, en relación con los productos digitales, audibles y televisivos, incluyendo los que tienen acceso a través de plataformas de streaming, con el objetivo de que las familias y los entornos laborales asuman de manera racional, responsable y adecuada los materiales diversos que se ofrecen mediante estos recursos tecnológicos, pues, tal como lo menciona Morales (2020):

Las relaciones de ayuda como parte de las funciones propias de la orientación se han enfocado en la creación de condiciones sociales, culturales y educativas que posibiliten el desarrollo de actitudes independientes, resilientes y competentes como herramientas para enfrentar creativamente los retos, los obstáculos y las adversidades que el contexto impone. (p. 186)

Finalmente, con esta reseña se pretende promover una conciencia crítica y un espacio de discusión disciplinaria, pues como profesionales de las ciencias sociales se debe asumir el compromiso de estar actualizados, tomando una actitud proactiva respecto a las circunstancias de una sociedad que enfrenta constantes cambios, que influyen en el bienestar integral de cada persona, independientemente de su historia de vida.

\section{Referencias}

Chernicoff, A. y Rodríguez, E. (2018). Autoconocimiento: una mirada hacia nuestro universo interno. https://biblat. unam.mx/hevila/Didac/2018/no72/6.pdf

Morales, J. (2020). El rol del orientador como agente dinamizador del escenario educativo y social. Innovaciones Educativas, 22(32), 184-198. https://doi.org/10.22458/ie.v22i32.2903

Valdés, A. (2014). Breve ensayo sobre el significado de la vida y de la muerte. https://www.researchgate.net/ publication/327219616_Breve_ensayo_sobre_el_significado_de_la_vida_y_de_la_muerte 